\title{
EXCESO Y PECADO: CARACTERÍSTICAS DE LA v̋ß@ıৎ EN EL PSEUDO JUSTINO MÁRTIR
}

\section{CARLOS BLANCH}

Universidad Nacional de Villa María carlosblanch66@hotmail.com

Recibido: 04/10/18

Aceptado: 09/10/20

El mundo griego clásico condenó claramente la conducta desmesurada. Ejemplos de esto pueden hallarse en las obras de los grandes escritores clásicos, en una gradación que parte de la simple fanfarronería hasta acabar en el nivel más grave, la soberbia contra los dioses. Los escritos del Pseudo-Justino Mártir rescatan el concepto clásico de űß@ıs, resignificándolo para censurar a quienes se oponían a la ortodoxia cristiana.

Exceso / Jactancia / Pseudo Justino / Soberbia / Ortodoxia

EXCESS AND SIN: CHARACTERISTICS OF ÜßQIৎ IN PSEUDO-JUSTIN MARTYR

The classical Greek world made it clear its condemnation of the excessive behavior. Examples of this can be found in the great classical writers' works, shown in a gradation that starts off with simple boasting up to the most severe level of pride against the gods. Pseudo-Justin Martyr's writings rescue the classic concept of $\tilde{\beta} \beta \mathrm{\varrho} \varsigma$, redefining it to censor those who opposed Christian orthodoxy.

Excess / Boast / Pseudo-Justin / Arrogance / Orthodoxy 


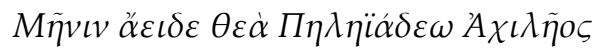

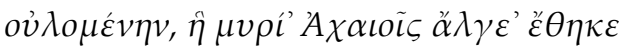

La cólera canta, oh diosa, del Pelida Aquiles, maldita, que causó a los aqueos incontables dolores... ${ }^{1}$

Con estas palabras principia el canto I de la Ilíada, palabras que describen el núcleo a partir del cual se desarrolla gran parte del argumento de esta magna obra: el enojo del valeroso hijo de Tetis. Sin embargo, el tema que en realidad da inicio al poema no es la cólera del héroe sino la condena implícita a la actitud soberbia e inmoderada de Agamenón, quien lo despoja de Briseida para compensar -injustamente, por cierto- la pérdida de parte de su propio botín. Es este proceder del líder de los aqueos el que suscita el repudio tanto de los personajes que intervienen en el posterior debate como el de aquellos que, a lo largo de los siglos, han escuchado o leído estos versos. Es la soberbia, la desmesura, la arrogancia insolente y violenta, lo que se opone

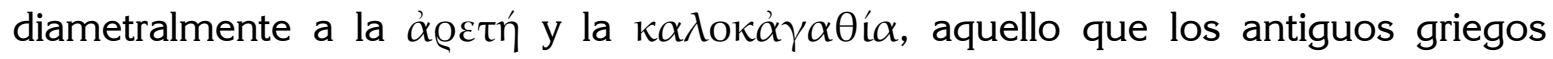
consideraron como uno de los peores defectos de la personalidad ${ }^{2}$.

Amante de la armonía y el equilibrio, la actitud helénica ante toda conducta excesiva fue la censura; baste mencionar, como ejemplo de lo dicho, una de las famosas máximas délficas grabadas en los dinteles del templo de Apolo: $\mu \eta \delta \dot{\varepsilon} v \alpha ̋ \gamma \alpha v$. Por tratar en este artículo de la condena del exceso en los planos literario y teológico, nos limitaremos a analizar la perspectiva que sobre el tema tienen los autores griegos clásicos más relevantes, para luego examinar en algunas de las obras más destacadas del Pseudo Justino cómo el pensamiento cristiano resignificó la condena de la desmesura en el plano teológico.

Se advierte en los autores clásicos -en aquellos casos en que los personajes involucrados presentan algún tipo de actitud inmoderada- una cierta gradación de la conducta excesiva, que va desde la simple fanfarronería hasta la insolencia arrogante contra los dioses o sus designios. Propondremos aquí tres conceptos que se repiten con frecuencia en estas obras, los cuales presentan un orden de gravedad creciente:

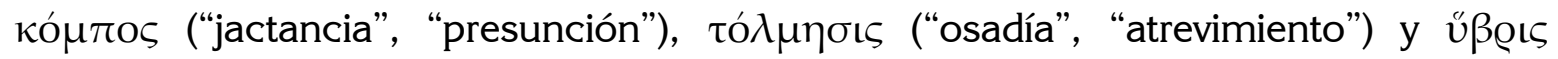
("violencia", "insolencia").

\section{Primer grado de desmesura: la altivez}

Ejemplo del primero de estos casos lo encontramos en el séptimo libro de la Historia de Heródoto, en la cual el soberano persa Jerjes reprocha a Demarato la jactancia griega frente a un ejército muy superior con estas palabras: 


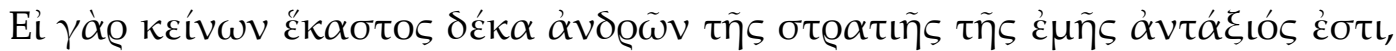

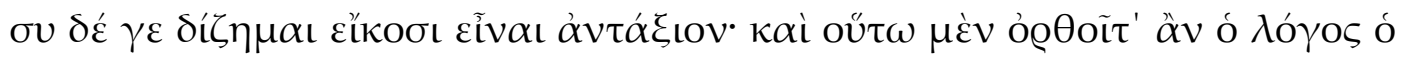

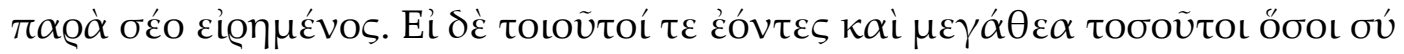

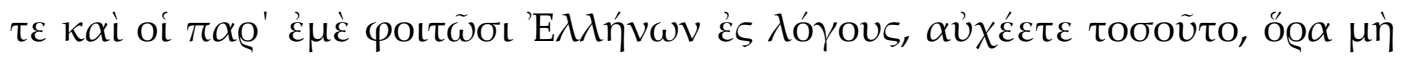

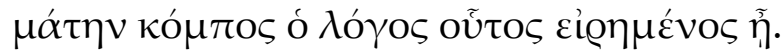

Si cada uno de ellos equivale a diez hombres de mi ejército, espero que, desde luego, tú valgas por veinte, ya que, así, podría ser cierta la afirmación que has hecho. Ahora bien, si, con unas cualidades personales y físicas como las tuyas y las de los griegos que suelen entrevistarse conmigo, os vanagloriáis tanto, ten cuidado, no vaya a ser que esa afirmación que has hecho resulte una vana fanfarronada ${ }^{3}$.

En una reflexión que resume la perspectiva helénica sobre este tema, el mismo autor expuso los riesgos que para cualquier hombre conlleva el pretender ser más de lo que su condición le permite:

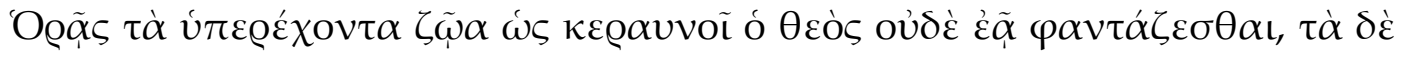

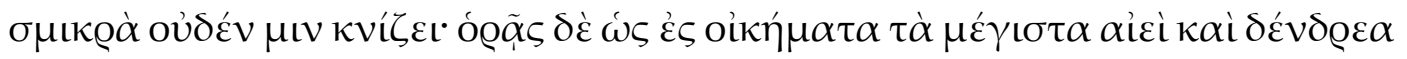

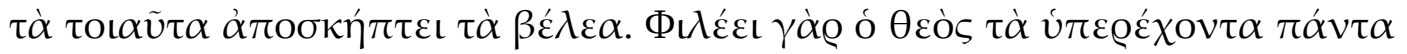

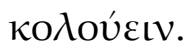

Puedes observar cómo la divinidad fulmina con sus rayos a los seres que sobresalen demasiado, sin permitir que se jacten de su condición; en cambio, los pequeños no despiertan sus iras. Puedes observar también cómo siempre lanza sus dardos desde el cielo contra los mayores edificios y los árboles más altos, pues la divinidad tiende a abatir todo lo que descuella en demasía ${ }^{4}$.

Un siglo después del historiador de Halicarnaso, Calímaco expresó también el mismo rechazo a esta actitud con palabras simples pero contundentes:

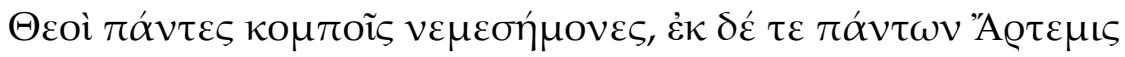

Los dioses todos a los fanfarrones no los soportan, y de entre todos Ártemis... ${ }^{5}$

\section{Segundo grado de la desmesura: la osadía}

En Antígona, Sófocles pone en boca del coro la consideración que merecía quien incurriera en la osadía, segundo de los términos propuestos y siguiente escalón en la gravedad de la desmesura. Allí se registra no sólo una enfática condena del atrevimiento 
-al que, a diferencia de la jactancia, se le atribuye además el demérito de incitar al mal obrar-, sino que también explicita el castigo que debería imponerse al que se atreva a actuar transgrediendo los límites que le corresponden:

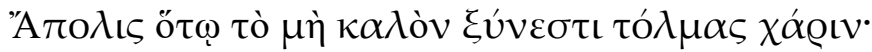

Desterrado sea aquel que, debido a su osadía, se da a lo que no está bien ${ }^{6}$.

Esquilo también expuso la consecuencia que para el titán Prometeo tuvo su osadía, esta vez con un resultado mucho más funesto para el culpable por tratarse de una transgresión, no a las normas sociales establecidas, sino a los mandatos del mismo Zeus:

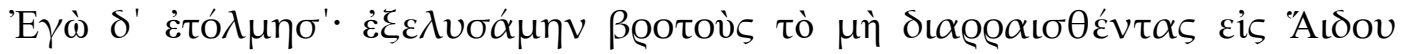

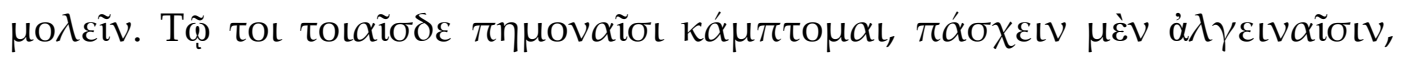

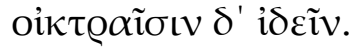

Yo me atreví; libré a los mortales de ser aniquilados y bajar al Hades. Por ello, estoy sometido a estos sufrimientos, dolorosos de padecer, compasibles cuando se ven?

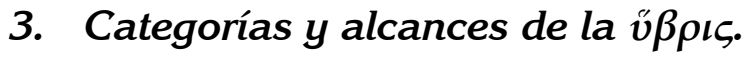

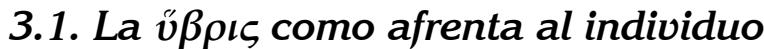

El tercer y más grave caso de conducta desmesurada queda indicado por el concepto de úßoıs. Una consulta en los diccionarios nos dirá que este término puede traducirse como "arrebato", "tratamiento insolente"9, "ultraje"10, "exceso" ${ }^{11}$, pero abarca mucho más; en el marco del léxico neotestamentario comprende también los significados de "insulto"12, "perjuicio"13 y "afrenta"14. Es un término polisémico, cuyo sentido se extiende a muchas esferas de aplicación: social, religiosa, incluso sexual ${ }^{15}$. Eurípides plantea un caso de üßoı s en Alcestis donde la culpa recae en Heracles, quien actúa de manera desmesurada y ofensiva al comer y beber, coronarse con una guirnalda y disfrutar de la hospitalidad de una casa en duelo. No importa que el héroe ignore la situación trágica que vive su anfitrión; el simple hecho de comer y beber cuando el resto de los presentes ayunan y penan es visto como una conducta excesiva digna de censura $^{16}$. Debido a esta gran amplitud semántica y a los fines del presente artículo, propondremos tres categorías graduales del concepto de űß@ı que delimitarán más precisamente su sentido.

La primera de ellas es la úß@ıৎ como ultraje contra el individuo. Son varias las obras literarias en las cuales se presenta esta perspectiva. Homero pone en boca de un 
despechado Aquiles palabras de condena para quien se atreve a ultrajar con violencia a su semejante:

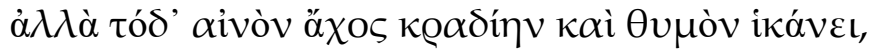

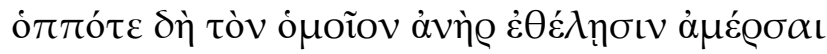

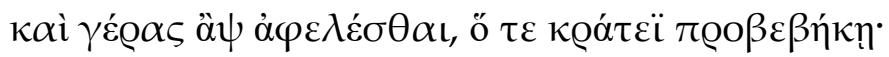

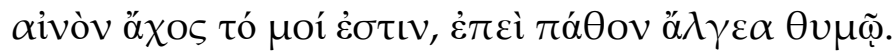

Esta atroz aflicción llega al corazón y el aliento cada vez que al semejante un hombre está dispuesto a arrebatarle la parte, es decir, a despojarle, ése que detenta el poder.

Una atroz aflicción es eso para mí, después de los dolores padecidos ${ }^{17}$.

Un concepto similar expresó Hesíodo con la fábula del halcón y el ruiseñor. Esta breve fábula está dirigida "a los reyes", es decir, a quienes tienen más fuerza y poder y, por ello, están más expuestos a la tentación de cometer atropellos contra los de más humilde condición, pero poco más adelante extiende su alcance de modo general a todos los hombres:

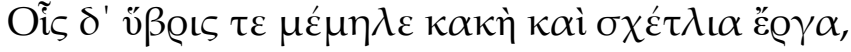

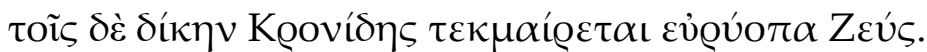

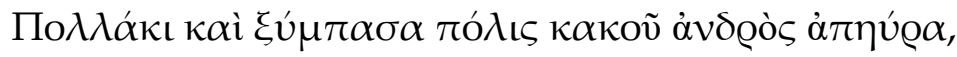

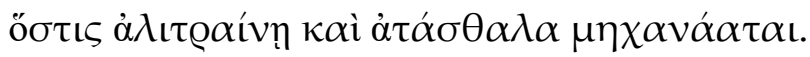

A quienes en cambio sólo les preocupa la violencia nefasta y las malas acciones, contra ellos el Crónida Zeus de amplia mirada decreta su justicia. Muchas veces hasta toda una ciudad carga con la culpa de un malvado cada vez que comete delitos o proyecta barbaridades ${ }^{18}$.

La idea de la úßoıৎ como un hecho de violencia y ultraje al semejante se encuentra también en los relatos míticos, como el de Sísifo ${ }^{19}$, quien fue condenado eternamente a empujar una enorme roca cuesta arriba de una montaña; cuando casi alcanzaba la cima, la roca resbalaba y rodaba hasta abajo, debiendo recomenzar nuevamente desde la base. Aunque Homero no da una razón para tal suplicio, ya en la Antigüedad se propusieron distintas explicaciones, entre las cuales una lo atribuía a la inmoderada ambición de Sísifo por acrecentar ilegítimamente sus riquezas asesinando a los viajeros y caminantes que se hospedaban en su casa, conducta execrable a ojos de un griego de la época clásica, para quien el deber de hospitalidad era una obligación sagrada. 


\subsection{La v́ßpı como violación de las normas sociales}

La segunda categoría presenta a la úß@ıৎ bajo un aspecto de mayor gravedad: como un ultraje a la sociedad. Medio siglo después de la muerte de Eurípides, Demóstenes incluyó la figura de la ưßoıs en un código legal, definiéndola como una conducta violatoria "del principio de igualdad en el marco social y jurídico de las relaciones entre los hombres" ${ }^{20}$, y pasible de ser castigada, en los casos más graves, con la pena de muerte. Esta regulación legal fue la formalización de una condena social contra la ưßıı que ya contaba con un extenso antecedente. Homero había expresado que Zeus őt $\varepsilon$

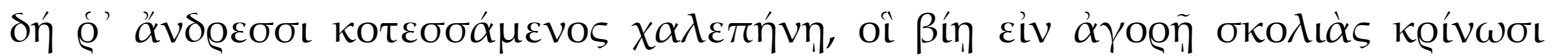

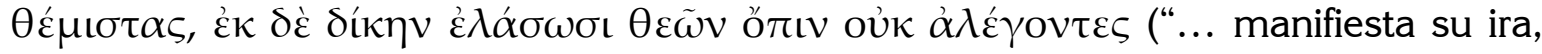
rencoroso, contra los hombres que en la plaza dictan sentencias torcidas abusando de su poder y destierran la justicia sin ningún miramiento por los dioses") ${ }^{21}$. Por su parte Hesíodo, quien ya nos brindara un ejemplo de la condena de la úßoıs en cuanto ofensa contra el individuo, también advierte contra la üßeıs como ofensa contra el cuerpo social. La persona que exhibe una conducta violenta, despectiva y arrogante no sólo atenta contra su semejante, sino también contra la sociedad misma, ya que en la mentalidad griega el hombre no podía concebirse aisladamente de la sociedad. En una época en la cual la fuerza de los poderosos tenía pocos reparos, la única garantía de equilibrio y mesura descansaba en la siempre vigilante mirada de los dioses. Así, para evitar este mal en las relaciones entre los poderosos y los débiles

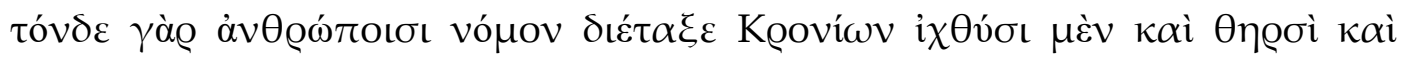

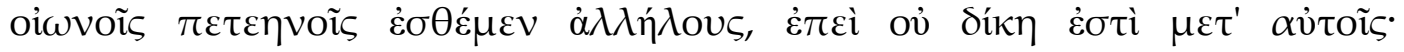

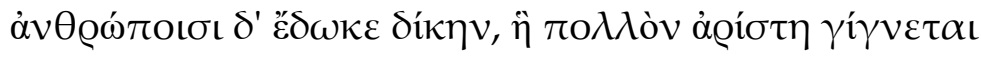

... esta ley impuso a los hombres el Cronión: a los peces, fieras y aves voladoras, comerse los unos a los otros, ya que no existe justicia entre ellos; a los hombres, en cambio, les dio la justicia que es mucho mejor ${ }^{22}$.

Sin embargo, los antiguos se percataron prontamente de la posible contradicción entre las leyes humanas y las divinas. Sófocles planteó agudamente este dilema en Antígona, presentando un interrogante que conduce a un aparente callejón sin salida: si la violación de la ley implica que el transgresor se considera por encima de ella y por ende incurre en un acto de úßoıs, cंcuál ley hay que obedecer -y cuál violar- en el caso de que los estatutos divinos y los humanos entren en conflicto? Este es el difícil predicamento en el que se encuentra la protagonista que da su nombre a la obra. $\mathrm{Si}$ obedece la orden de Creonte, incurrirá en una grave falta al descuidar los ritos religiosos que los dioses instituyeron para honrar a los difuntos; si da sepultura a Polinices, violando el edicto real, infringirá la ley, única garantía de la armonía y el bienestar social. Ya sea que se incline por una o por otra opción el acto de úßoıs -aun cuando sea 
involuntario como en el mencionado caso de Heracles en Alcestis- es ineludible. Empero, aunque la religiosidad de Sófocles no se revela tan acentuada como la de su predecesor Esquilo, su razonamiento no podía equiparar la ley humana a la divina; ante la disyuntiva, considera que es más grave una falta contra la divinidad que la violación de las leyes creadas por el hombre. Por ello en Antígona se decanta por priorizar el mandato de los dioses, mostrándolo como lo más acertado y transmitiendo implícitamente la idea de que una adhesión demasiado rígida a las leyes humanas puede conducir a la desgracia al constituirse en una conducta que dé lugar a la úß@ıs.

\subsection{La v́ $\beta \rho \iota \varsigma$ como ofensa a la divinidad}

Este último aspecto -la űß@ı como el exceso insolente del hombre que desafía a los dioses- es el tercer y más severo grado de conducta desmesurada. La concepción del hombre como un ser cuya esencia está enmarcada dentro de unos límites que no es sensato trasponer domina la mentalidad griega, de ahí que cualquier intento de superar la línea que separa a los simples mortales de los bienaventurados Olímpicos sea considerado como un atentado al orden natural impuesto por su suprema potencia. Pretender ser igual o incluso más que los dioses, desafiar su voluntad, ofender su divinidad, son rasgos máximos de v̋ß @ıৎ y ameritan un castigo que reubique al ofensor en la condición que le corresponde. Son numerosos los ejemplos de este tipo en la literatura griega de todas las épocas; presentaremos a continuación unos breves pasajes de algunos autores clásicos que exponen lo que acabamos de referir.

El primero de ellos es Homero. En la Ilíada el poeta presenta el caso de Níobe, quien fue madre de una docena de hijos. Al considerar que, por haber dado a luz tantos hijos, su fecundo vientre la hacía superior a Leto, madre de dos dioses, incurrió en üßoıs y fue castigada por Apolo:

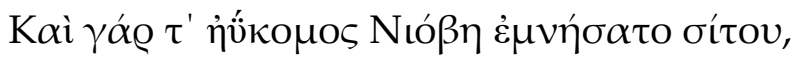

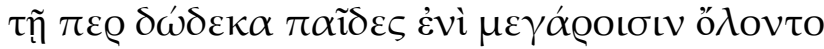

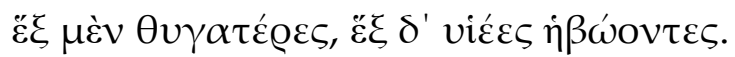

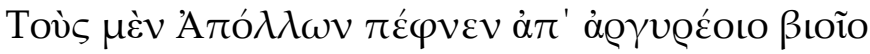

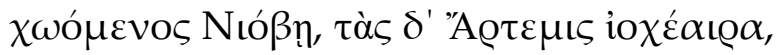

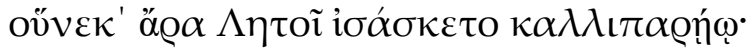

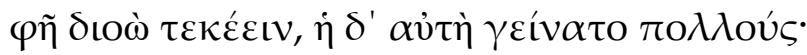

También Níobe, la de hermosos cabellos, se acordó del alimento, aquella Níobe a la que doce hijos se le murieron en el palacio, seis hijas y seis hijos en plena juventud.

A éstos los mató Apolo con los disparos del argénteo arco, irritado contra Níobe, y la sagitaria Artemis a aquéllas, 
por haber pretendido igualarse a Leto, la de bellas mejillas.

Decía que ésta sólo había alumbrado a dos y que ella a muchos... ${ }^{23}$

La üßoı contra los dioses también puede darse a nivel colectivo, tal cual lo registra Calímaco. En el fragmento LXXV refiere la destrucción de la isla de Ceos por la insolencia e impiedad de su pueblo:

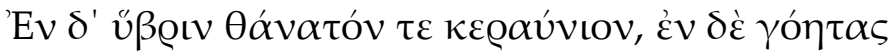

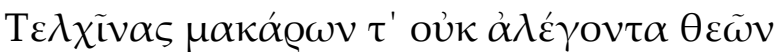

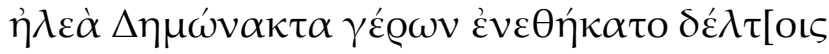

$\kappa \alpha \grave{i} \gamma \varrho \eta \tilde{v} \nu \mathrm{M} \alpha \kappa \varepsilon \lambda \omega \dot{\omega}, \mu \eta \tau \varepsilon \dot{\varrho} \alpha \Delta \varepsilon \xi \iota \theta \dot{\eta}\rceil \varsigma$,

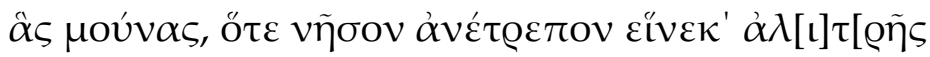

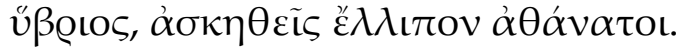

Y el anciano recogió en sus tablillas la soberbia y la muerte por rayo

y a los brujos Telquines y a Demonacte,

quien desdeñara insensato a los dioses dichosos,

y a la vieja Macelo, de Dexítea la madre,

únicas dos que dejaron sin daño los que nunca perecen

la vez que la isla volcaron en razón de una (culpable) insolencia ${ }^{24}$.

Desafiar a los dioses es otro rasgo de la conducta extrema que realiza quien está poseído por la ưß@ıs. Es el caso de Erisictón, quien no tuvo reparos en talar el bosque consagrado a Deméter para construirse una sala de banquetes, respondiendo con insolencia a las súplicas que ante este sacrilegio le dirigiera la misma diosa ${ }^{25}$. Quien los desafía no quiere tan sólo ubicarse a la altura de los Inmortales sino desplazarlos para ocupar su lugar. La mítica batalla entre titanes y dioses y el triunfo final de estos últimos tenía un significado claro para los antiguos: era el triunfo de las fuerzas del orden, la armonía y el equilibrio sobre la fuerza bruta, la violencia y el caos. Todo aquel que atenta o pretende ir en contra de este orden instaurado por los dioses está, por consiguiente, reviviendo esta violenta brutalidad de los titanes, esta ű $\beta \iota \varsigma$ que no reconoce límites. $\mathrm{Al}$ atentar contra los fundamentos mismos del orden natural, el violento está alejándose de los parámetros fijados para él como criatura finita. Por ello, Hesíodo menciona la suerte que corrió Menecio como una advertencia a todo aquel que se atreva a propasarse con las deidades:

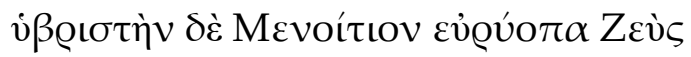

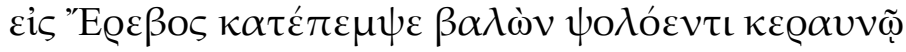

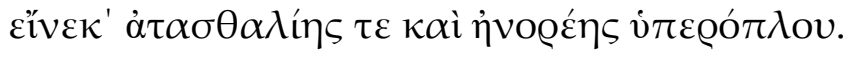


Al violento Menecio, Zeus de amplia mirada

le hundió en el Érebo, alcanzándole con el ardiente rayo, por su insolencia y desmedida audacia ${ }^{26}$.

La persistencia de esta idea puede verificarse siglos después de Hesíodo en las Argonáuticas de Apolonio de Rodas. En este relato de las peripecias que atraviesan los Argonautas en su búsqueda del vellocino de oro se destaca la actitud soberbia de Idas, quien partiera con Jasón hacia la Cólquide. Idas declara con insolencia que ni siquiera los dioses podrían oponérsele, lo que le vale los reproches de sus compañeros:

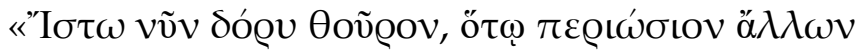

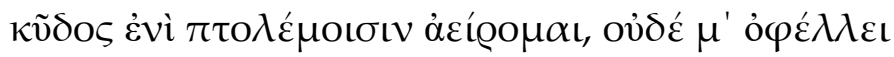

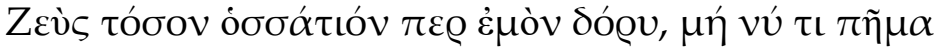

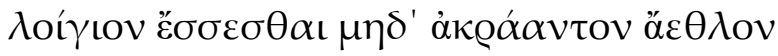

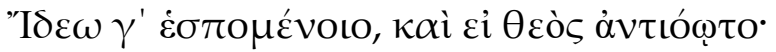

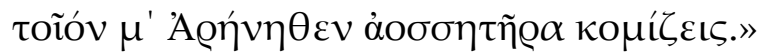

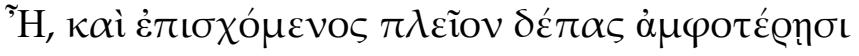

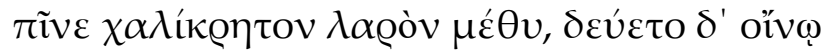

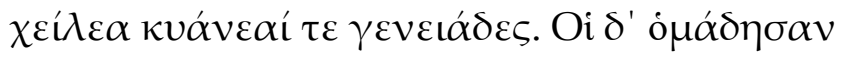

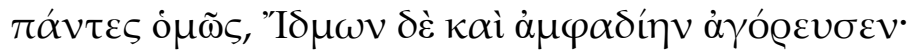

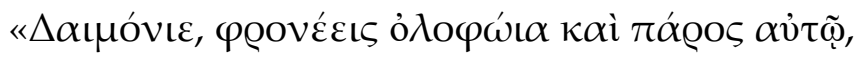

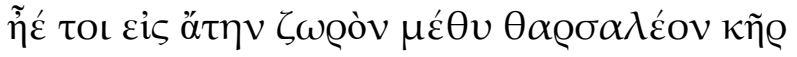

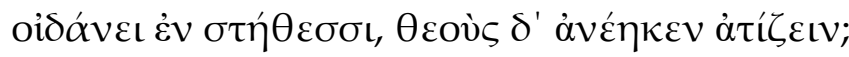

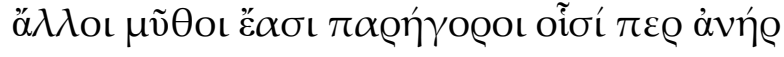

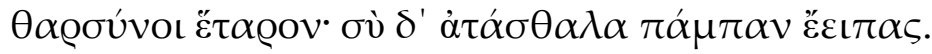

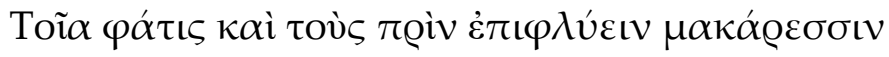

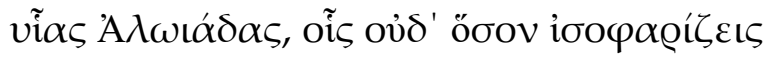

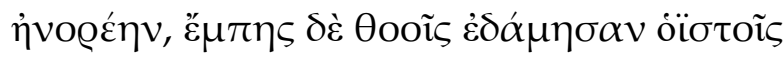

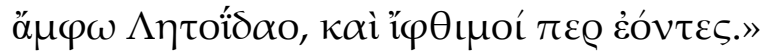

"Juro ahora, por mi lanza impetuosa, con la que alcanzo

en los combates mayor gloria que los demás -y ni siquiera

Zeus me engrandece tanto como mi lanza-, que no habrá funesta desgracia ni

prueba irrealizable]

mientras te siga Idas, aunque un dios se antepusiera.

Tal valedor llevas en mí desde Arene."

Dijo y, sosteniendo con ambas manos

su copa rebosante, bebió el delicioso vino puro

y regó con el vino sus labios y su negra barba. Los otros vociferaron todos a un

tiempo e Idmón le replicó abiertamente: 
"Desdichado, ctienes ya desde antes pensamientos aciagos para ti, o acaso para tu desgracia el vino puro inflama tu osado corazón en el pecho y te ha empujado a menospreciar a los dioses?

Otras palabras hay alentadoras, con las que podría un hombre animar a un compañero. Mas tú has dicho cosas del todo orgullosas. Parecidas injurias es fama que en otro tiempo lanzaron también contra los inmortales los hijos de Aloeo, a los que ni siquiera te igualas en hombría, y sin embargo, aunque eran valerosos, fueron ambos derribados por los veloces dardos del Letoida"27.

No es esta la única ocasión en la que Apolonio registra la violencia y la insolencia que embargan a Idas; la conducta soberbia parece ser un rasgo característico de este belicoso héroe. También Homero da cuenta de cómo este guerrero

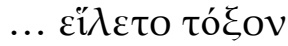

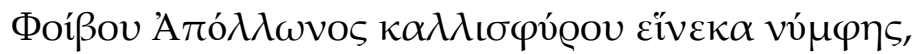

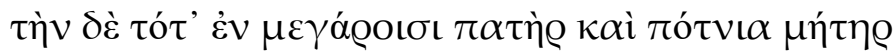

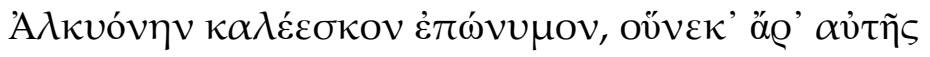

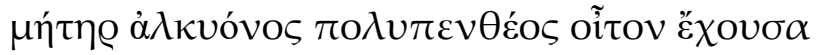

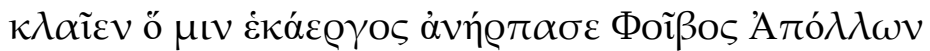

... tomó el arco

ante Febo Apolo en porfía por la doncella, de bellos tobillos, a la que entonces en su palacio su padre y su augusta madre solían llamar Alcíona como apodo, porque por ella su madre, con el mismo hado que el gimiente alción, lloraba desde que la había raptado el protector Febo Apolo ${ }^{28}$.

Nótese aquí la prueba más clara de la űß@ı de Idas: atreverse a desafiar con el arco nada menos que a Apolo, dios conocido con el sobrenombre de "Flechador". Ante tamaña afrenta se esperaría que este personaje sufriera un castigo ejemplar, pero ni Homero ni Apolonio cuentan cuál fue su fin. Para saber cuál fue su suerte debe leerse a Píndaro y a Teócrito. Ambos relatan la muerte de Idas consumido por el rayo de Zeus luego de que se atreviera a enfrentarse con uno de los Dioscuros:

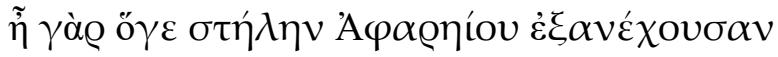

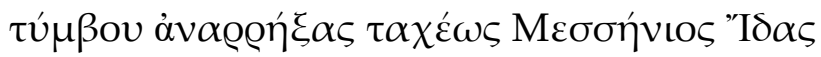

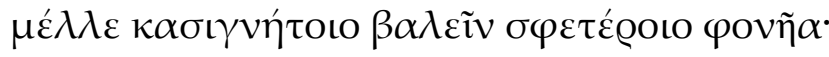

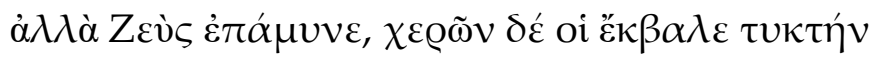

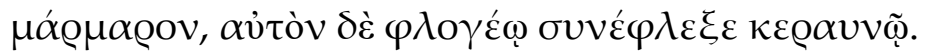


Pues Idas el Mesenio velozmente arrancando

la estela que se alzaba sobre la tumba de Afareo,

fue a herir con ella al asesino de su hermano;

pero Zeus protegió a éste, le arrancó de las manos el labrado

mármol y con un rayo ardiente lo abrasó ${ }^{29}$.

El relato se completa con la advertencia con que Píndaro finaliza esta historia: $\chi \alpha \lambda \varepsilon \pi \dot{\alpha}$

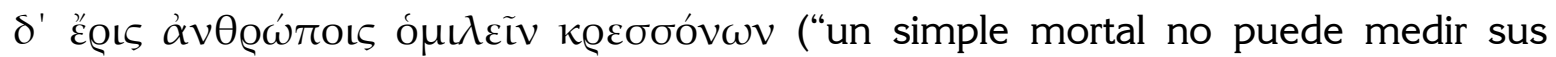
fuerzas con aquellos que proceden de una estirpe divina" ${ }^{30}$ ). Intentarlo es caer en la soberbia y su castigo es la muerte, como acota Carmen Verde Castro:

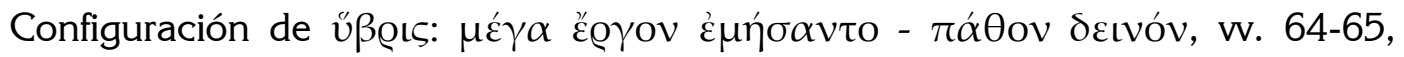
según el concepto solónico-pindárico-esquileo de culpa y castigo que viene de Zeus. Píndaro esquiva el continuum narrativum de la epopeya. Se dan datos aislados, salteados, retrospectivos: morada ultraterrena, muerte de Cástor, matadores, crimen. Se sigue el proceso inverso con el castigo de los culpables. Vaivén pendular: los Afaretidas son presentados como delincuentes y sacrílegos. Ahora, la víctima es Pólux. Pero hay una radical distinción entre Pólux, inmortal, invulnerable, y Cástor, precario y mortal. Pólux mata a su atacante, Linceo. Hay

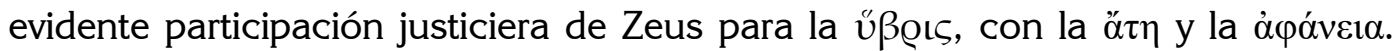
Aniquilación de los culpables y $\gamma v \omega ́ \mu \alpha$ que rubrica el todo. El fin del epodo cuarto contiene, precisamente, la aseveración más rotunda y aplastante del poder de Zeus sobre los Afaretidas, cuyos cadáveres se consumen con el rayo ígneo en absoluta soledad. Gran pausa de sentido frente a estas cenizas, últimos restos de una gran rebeldía humana. En el v. 72 se palpa, tras el aforismo, la fragilidad del hombre frente a la superioridad divina ${ }^{31}$.

\section{El léxico de la desmesura en el Pseudo Justino}

Para la sociedad pagana del período post-apostólico, asimilar el cristianismo no significó renunciar por completo a su sustrato cultural helenístico. Los apologetas y los Padres de la Iglesia fueron los primeros en intentar la conciliación entre los fundamentos del pensar filosófico griego y los dogmas de la fe cristiana. En su afán por presentar una visión aceptable del cristianismo a las mentes paganas cultas, recurrieron a muchos elementos propios de la tradición griega, y lo mismo hicieron cuando tuvieron que defenderse de los ataques en contra de su fe. Así, el concepto de desmesura y sus grados, tal como lo definimos al principio, pasó a integrar el repertorio del pensamiento patrístico. A continuación, analizaremos su presencia y sentido en algunos de los escritos atribuidos a Justino Mártir.

Justino Mártir fue uno de los primeros apologetas cristianos, nacido a principios del siglo II. El prestigio de este Padre y la autoridad de sus escritos fueron tales que 
varias obras de carácter polémico se atribuyeron a su pluma, aun cuando un análisis de su estilo, temas tratados y objetivos revela claramente que proceden no sólo de distintos autores sino también de épocas diferentes, razón por lo cual de ahora en más nos referiremos a ellos como obras del Pseudo Justino. José P. Martín lo expone concisamente:

La heterogeneidad y el número de los escritos que los bibliotecarios antiguos cubrieron con el manto de protección de Justino Mártir han impedido, hasta hoy, que se les dedique la atención que cada uno de ellos merece. Son 12 tratados de diversa especie y pertenecientes a siglos diferentes, en un arco que va del segundo al sexto... ${ }^{32}$

Pero aún cuando la autoría de los escritos de Justino pueda ser cuestionada, el amplio espacio temporal establecido por los especialistas para su redacción (siglos II al VI) es prueba de la pervivencia del concepto en el pensamiento patrístico. Es posible reconocer, en los textos que hemos seleccionado, al menos tres destinatarios a los cuales el Pseudo Justino acusa de incurrir en una conducta desmesurada, no sólo en el sentido en que fue resignificada por el cristianismo -a saber, como sinónimo de pecado- sino también en el sentido clásico -la jactancia, el atrevimiento y la insolencia que empujan al hombre a transgredir sus límites e insultar a la divinidad-. Ellos son los paganos, los judíos y los cristianos cuyas ideas no se amoldaban a la doctrina ortodoxa.

El paganismo y el judaísmo fueron los dos grupos a los cuales el cristianismo tuvo que combatir para asegurar su supervivencia, y contra ellos se dirigieron gran cantidad de obras polémicas en los siglos II y III. El Diálogo con Trifón, cuya autoría es indiscutiblemente de Justino Mártir, es un ejemplo de este tipo de literatura que censuraba al judaísmo por su rechazo a aceptar el mensaje evangélico. Otros escritores cristianos destacados de estas primeras épocas, como Clemente de Alejandría en su Protréptico, también exhortaron a los paganos a convertirse a la nueva fe denunciando los vicios de sus creencias supersticiosas y demoníacas. En consonancia con esto, el escritor de la Epístola a Diogneto mantuvo el mismo tenor en su obra, rechazando las costumbres judías y paganas y calificándolas respectivamente como $\alpha \lambda \alpha \zeta$ oveí $\alpha$-un sinónimo de кó $\mu$ ros- y como üß@ıs.

Durante los dos primeros siglos de vida, el cristianismo tuvo un oponente formidable en el judaísmo. Aunque la distancia entre ambos se fue agrandando progresivamente, hubo quienes intentaron transpolar el carácter formal y legalista de la religión judía al seno del cristianismo, lo cual constituía un serio riesgo para éste. Sin embargo, a pesar de su enfrentamiento con el cristianismo, el judaísmo no es acusado más que de jactancia, un grado menor de desmesura. Como aclaramos poco más arriba, el escritor no usa el término kó $\mu \pi 0 \varsigma$ en estos textos sino su equivalente $\dot{\alpha} \lambda \alpha \zeta$ ové́ $\alpha$ - que mantiene la misma carga semántica. La presunción o jactancia es considerada por el autor como pura vanidad, poniendo como ejemplos las prácticas 
que los judíos tenían en alta estima y eran motivo de orgullo frente a los gentiles, pero a las que el cristiano considera inútiles:

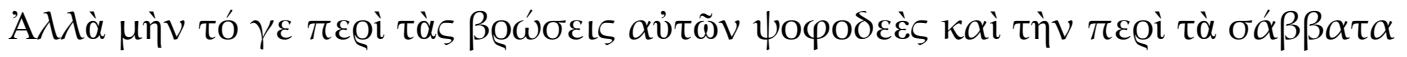

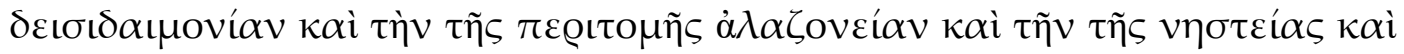

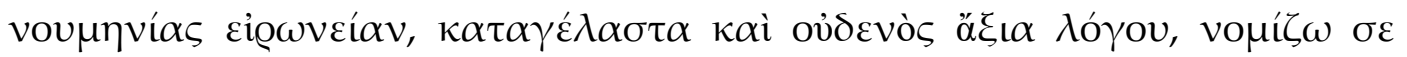

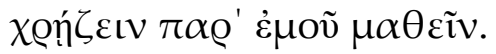

Pero ciertamente el escrúpulo acerca de sus alimentos, la superstición sobre el sábado, la jactancia de la circuncisión y el fingimiento del ayuno y el novilunio, ridículos e indignos de mencionar, considero que te es necesario aprenderlo de $\mathrm{mi}^{33}$.

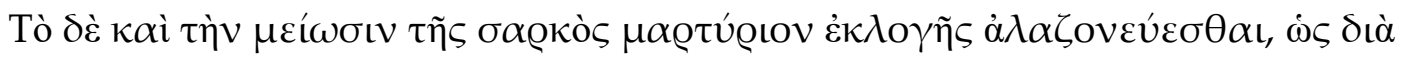

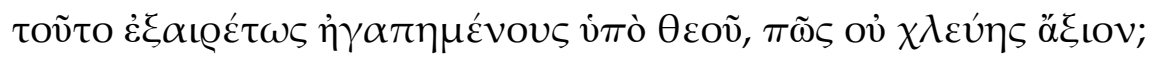

Pero jactarse de que la disminución de la carne es un testimonio de la elección, como si por medio de esto fueran especialmente amados por Dios, ċcómo no va a ser digno de burla? ${ }^{34}$

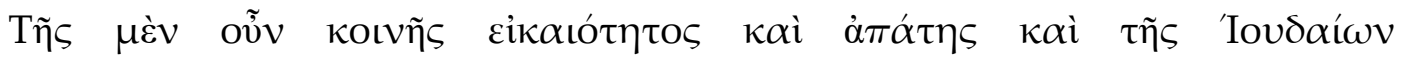

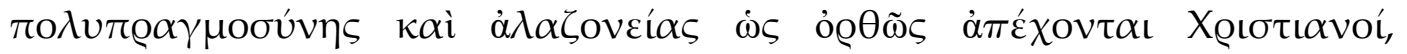

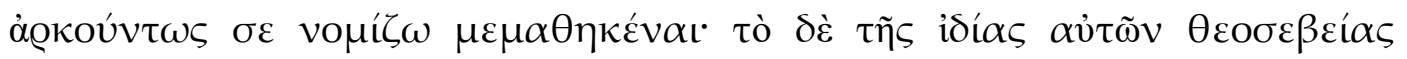

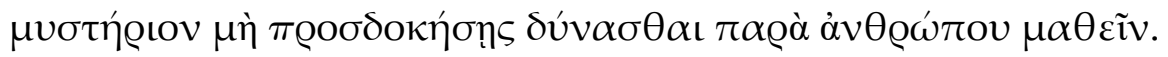

De la ligereza, astucia, intriga y jactancia que es común en los Judíos, de las que los Cristianos se mantienen correctamente apartados, considero que ya has aprendido suficientemente; pero del misterio de su particular culto divino, no esperes que pueda ser comprendido por el hombre ${ }^{35}$.

En otra epístola, se aconseja a los cristianos prevenirse contra la jactancia de ciertas personas, a las que se acusa de actuar de modo soberbio:

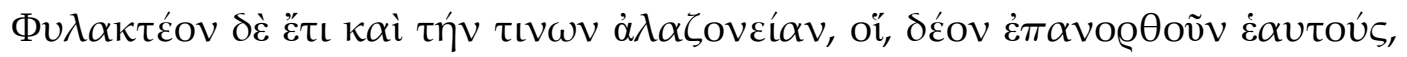

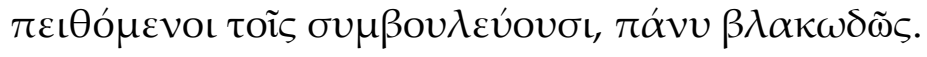

Hay que cuidarse aún más de la jactancia de algunos, los cuales, necesitando corregirse a sí mismos, son persuadidos por los que los aconsejan, actuando ciertamente de modo orgulloso ${ }^{36}$. 
Los reproches a los paganos adquieren otro tono, revistiendo mayor dureza. Aunque los judíos puedan ser acusados de jactancia, no puede negarse, sin embargo, que efectivamente conocen al Dios verdadero, aunque hayan rechazado a su Hijo. Pero los paganos carecen de la luz que proporciona la fe cristiana y por ello divagan acerca de Dios y su creación con palabras insolentes e ignorantes, lo que cae en la categoría de űß@ı. Ejemplo de lo dicho son las dos citas siguientes:

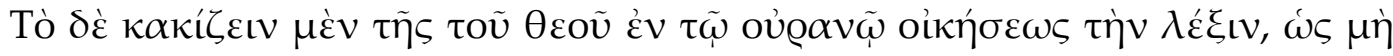

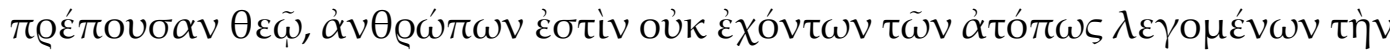

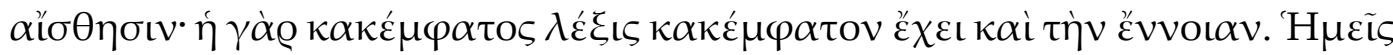

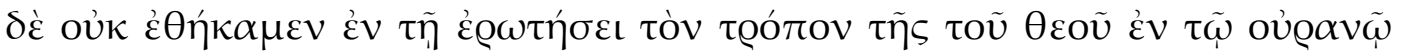

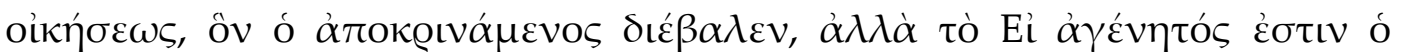

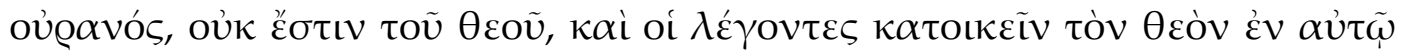

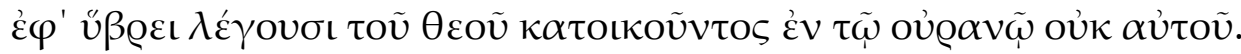

El censurar como impropia de Dios la expresión de que Él habita en el cielo, es propia de hombres que, absurdamente, no tienen idea de lo que dicen; pues una expresión incorrecta lleva también a una comprensión incorrecta. En cambio, nosotros no apuntamos en la pregunta al modo en que Dios habita en el cielo, lo cual censuró el que replicó, sino a esto: si el cielo es increado, no es de Dios, y los que dicen que Él habita en el cielo hablan insolentemente al decir que Dios habita en un cielo que no es de $\mathrm{E}^{37}$.

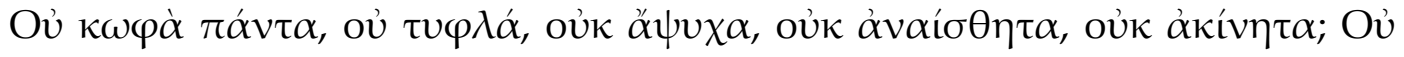

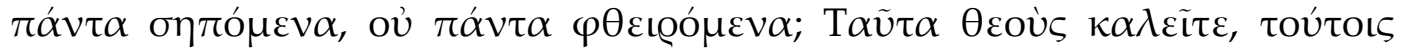

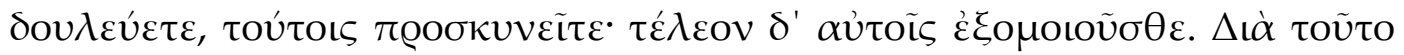

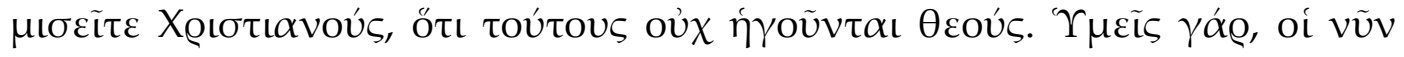

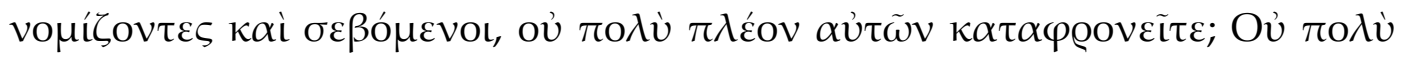

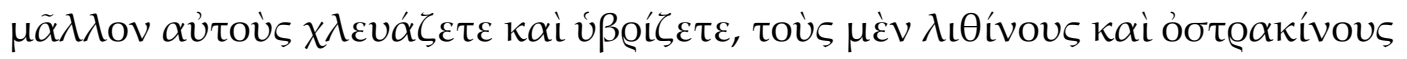

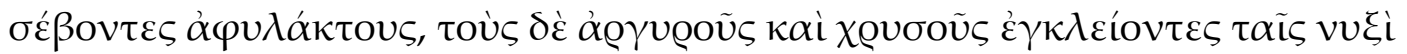

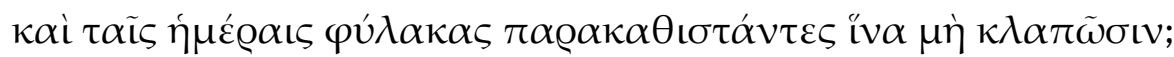

¿No son todas mudas, ciegas, inanimadas, insensibles, inmóviles? ¿No son todas corruptibles, que se descomponen? A estas cosas llamáis dioses, a éstas servís, a éstas adoráis; pero al final os parecéis a ellas. Por esta causa odiáis a los cristianos, porque no creen en estos dioses. Vosotros, pues, ¿no despreciáis en mayor medida a los que también ahora tenéis por venerables? ¿No los burláis y ultrajáis, más bien, dejando sin custodia a los venerables [dioses] de piedra y de barro cocido, pero encerrando por las noches a los de plata y oro, y de día poniéndoles al lado guardias para que no se los roben? ${ }^{38}$ 
Puede notarse en la última pregunta de la cita la concepción clásica de la úß@ıৎ como ofensa a los dioses, empleada aquí en tono irónico para polemizar con los paganos. Pero aun cuando el autor desprecie a los dioses de los idólatras, el hecho de mantener una actitud despectiva hacia ciertas imágenes de deidades por estar sus figuras hechas de piedra o barro y no de materiales nobles es una conducta considerada reprochable. Se evidencia aquí el resurgimiento de la noción que ya hemos visto en autores clásicos como Homero, Calímaco y Apolonio de Rodas, entre otros.

Sin embargo, las críticas más graves son las reservadas a los cristianos quienes, por el hecho de haber conocido la suprema Verdad revelada en el mensaje evangélico, cometen la falta más grave al intentar ir más allá de lo que la Palabra de Dios revela y la Iglesia estatuye. Entre los siglos IV y VI la discusión de ciertos dogmas fundamentales provocó numerosas opiniones en el seno eclesiástico, algunas de las cuales derivaron en posturas manifiestamente heréticas, mientras que otras eran vistas con sospecha. En un intento de frenar la difusión de estas ideas al interior de la Iglesia, el autor de la Expositio rectae fidei amonestó al lector de su obra a evitar el exceso que caracteriza al que pretende saber más de lo que Dios ha revelado. Cuestionar doctrinas tales como la doble naturaleza de Cristo y la autoridad de las Escrituras, o no reconocer las limitaciones del intelecto humano en lo que respecta al conocimiento de Dios y sus obras, son claros actos de üßeıs:

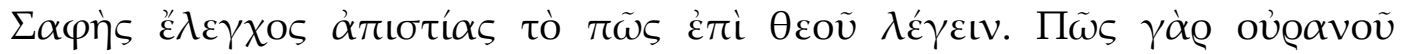

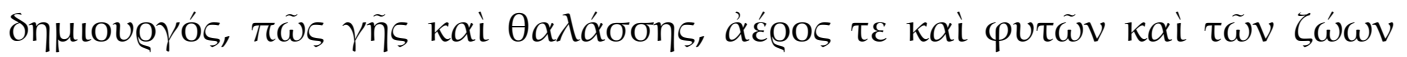

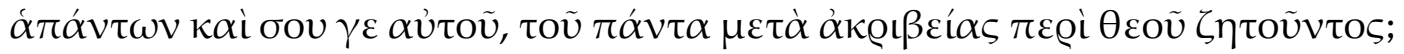

Es una clara demostración de incredulidad el querer hablar de algún modo acerca de Dios. ¿Qué se puede decir del Creador del cielo, de la tierra y el mar, del aire y de las plantas, de todos los animales y de ti mismo, que investigas con minuciosidad todas las cosas acerca de Dios? ${ }^{39}$

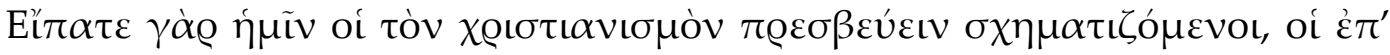

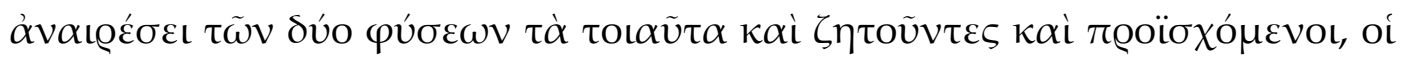

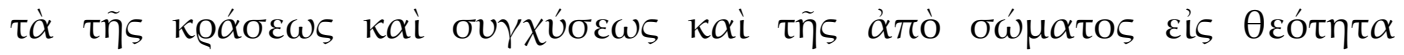

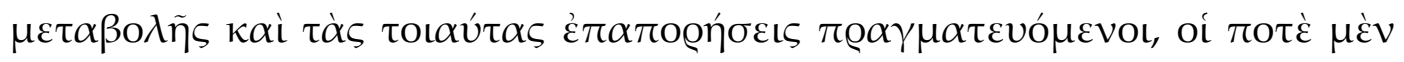

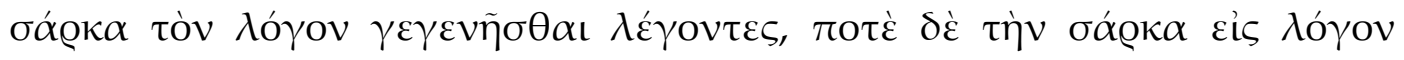

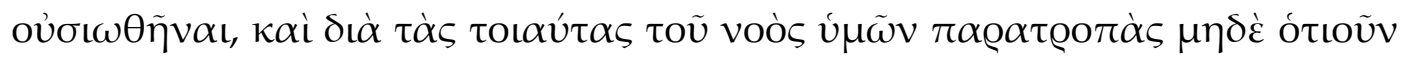

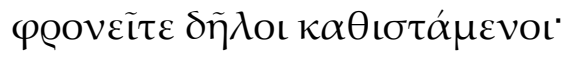

Decidnos, pues, vosotros que fingís honrar el Cristianismo, que por la refutación de [la doctrina] de las dos naturalezas no sólo indagáis sino que proponéis tales cosas, que os ocupáis en las [cuestiones] de la mezcla y la fusión, de la transformación del cuerpo en una naturaleza divina y de suscitar dudas sobre tales 
cosas, que unas veces decís que el Verbo se hizo carne y otras veces afirmáis que la carne fue substancializada en el Verbo, y mediante tales extravíos de vuestro entendimiento demostráis que ni siquiera entendéis lo que proponéis ${ }^{40}$.

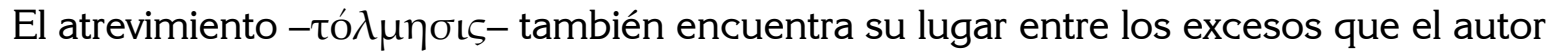
achaca a quienes transgreden los límites de lo que es posible al hombre conocer. Recordemos que en los autores clásicos la osadía era considerada una falta más grave que la simple jactancia porque implicaba no sólo un ego inmoderado sino también una proclividad hacia el mal obrar, algo contra lo que el cristiano tiene que estar muy precavido:

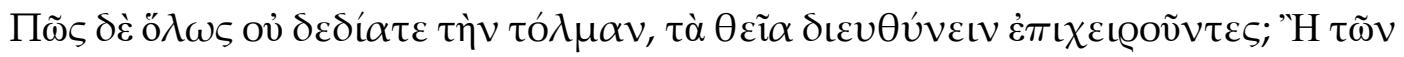

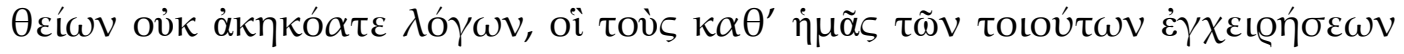

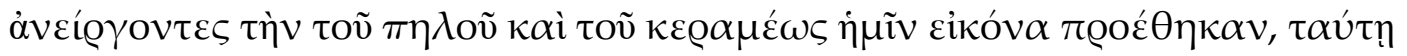

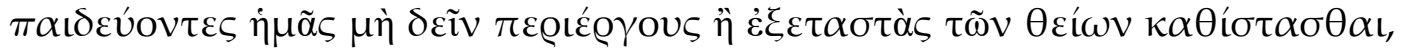

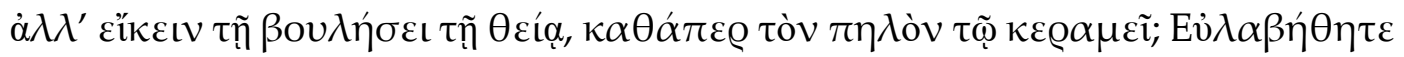

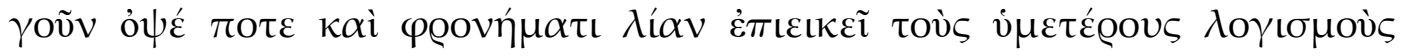

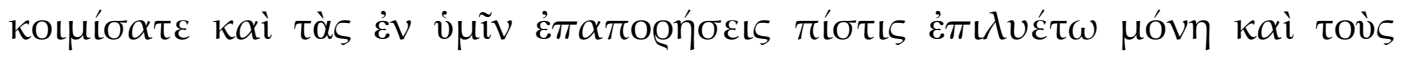

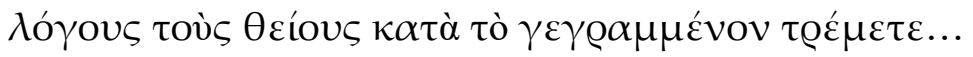

En resumen, ¿cómo no habéis de temer el atrevimiento de los que se atreven a corregir las cosas divinas? ¿O no habéis escuchado las palabras divinas, que los que rechazan tales intentos nos exponen la imagen del barro y del alfarero, enseñándonos con ellas que no es preciso dedicarse a curiosear o a rebuscar en los [misterios] divinos, sino ceder a la voluntad divina, como el barro con el alfarero? En efecto, aunque sea un poco tarde, sed prudentes y con una manera de pensar muy mesurada, apaciguad vuestros razonamientos y las dudas que tenéis, que sólo debilitan la fe, y temed las palabras divinas, según está escrito ${ }^{41}$...

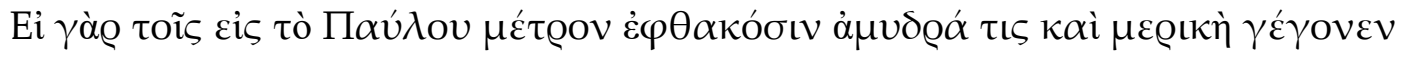

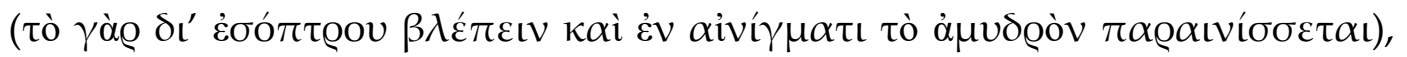

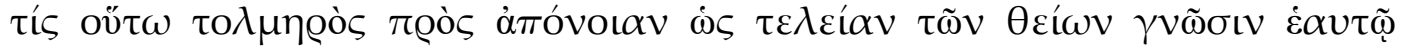

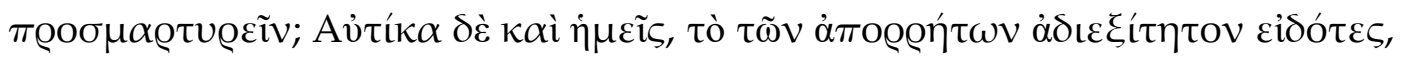

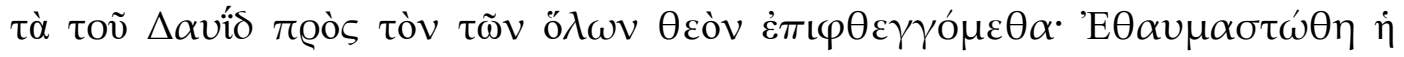

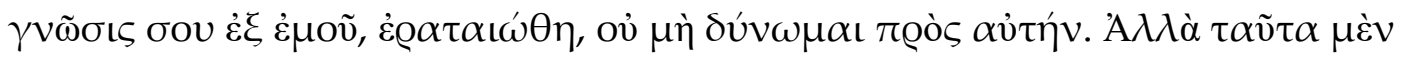

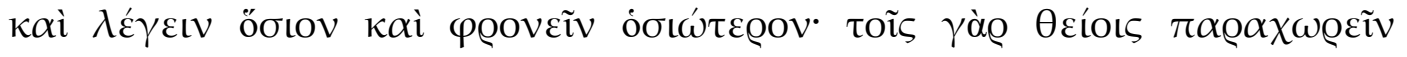

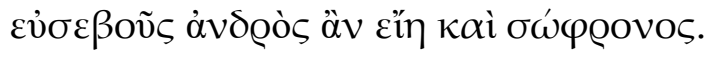

Si, pues, para aquellos que han alcanzado la medida de Pablo se presenta como algo confuso y parcial (pues al ver como por medio de un espejo y veladamente, 
lo obscuro se da a entender a medias), cquién, por temeridad, será tan atrevido como para confirmar que [tiene] en sí mismo el conocimiento perfecto de los [misterios] divinos? Ahora también nosotros, viendo que las cosas inefables son inexplicables, invocamos las [palabras] de David con relación al Dios de todo: $E l$ conocimiento de Ti fue objeto de asombro en mí, fue afirmado, de ninguna manera puedo penetrar en él. Pero no sólo hay que ser santo para decir estas cosas, sino más santo aun para pensarlas, pues el renunciar a los [misterios] divinos es [propio] de un hombre piadoso y prudente ${ }^{42}$.

Sin embargo, la condena del escritor contra la actitud desmesurada encuentra su expresión más dura en las siguientes palabras:

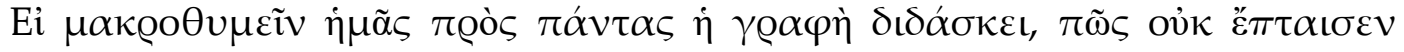

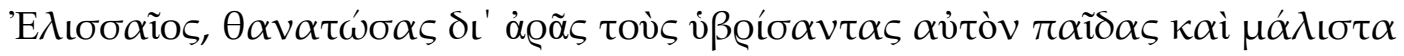

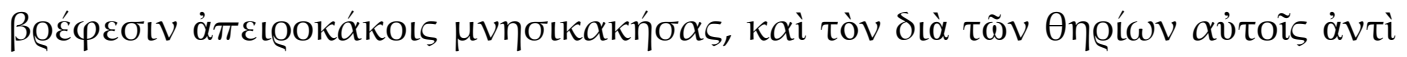

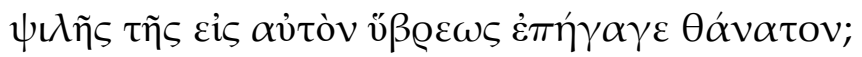

Ӓ

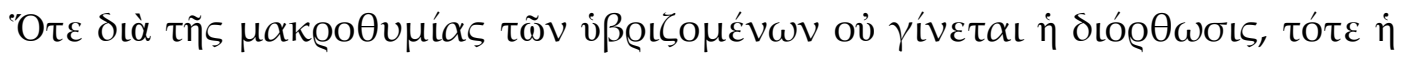

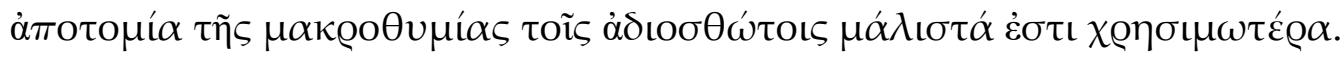

Si la Escritura nos enseña a ser pacientes con todos, ¿cómo no cayó en falta Eliseo quien -exageradamente- dio muerte a los niños que lo ofendieron y, como si esto fuera poco, se enojó con unos infantes traviesos y provocó la muerte por medio de las fieras a los que lo ofendieron llamándolo calvo?

Respuesta

Puesto que la corrección no se da a través de la paciencia para con los insolentes; en ese caso la dureza para con los díscolos es más provechosa que la paciencia. ${ }^{43}$

La intransigencia del autor en relación al trato que debe dispensarse a los que caen en la ǔß@ıs, evidenciada en la dura respuesta a la cuestión planteada, debe entenderse a la luz del episodio bíblico que motiva la pregunta. El profeta Eliseo maldijo a los jóvenes que se burlaban de su calvicie y unas osas furiosas salieron del bosque y los mataron. A primera vista, pareciera que el acto desmesurado es el del profeta -tal como lo da a entender el interrogador- por causar la muerte de los jóvenes por una simple burla. Pero el autor considera esta falta de respeto al profeta como una ofensa a Dios, a quien el profeta representa; burlarse de un siervo de Dios es ofender a Dios mismo. Por lo tanto, quien así haga no debe ser compadecido ni tratado con tolerancia, sino que se le debe aplicar el máximo rigor para que proceda a la corrección. 


\section{Conclusión}

Ateniéndonos, pues, a lo oportunamente expresado por José P. MARTín acerca del amplio período de tiempo atribuido a los escritos del pseudo Justino, es posible concluir que la utilización del concepto clásico de la desmesura en estos escritos fue propiciada por la potencia que aún conservaba la cultura grecorromana en la sociedad educada de aquellos siglos. En ellos, se destaca la readaptación del concepto clásico de desmesura como medio para censurar las actitudes impías y las desviaciones dogmáticas. La insistencia en advertir a los lectores acerca de la falta de moderación, el exceso y la soberbia del intelecto humano que pretende conocer los misterios divinos más allá y por fuera de la revelación contenida en la Escrituras, encuentra su fundamento en los graves problemas doctrinales que marcaron la historia de la Iglesia entre los siglos II y VI. La advertencia del pseudo Justino se constituye, entonces, en un intento de frenar las especulaciones teológicas heterodoxas, que amenazaban no sólo la estructura dogmática de la Iglesia sino también el frágil equilibrio político de la misma. La Iglesia oriental lidiaba con cismas y herejías y buscaba fórmulas que le aportasen una precaria estabilidad; la Iglesia de Roma asumía cada vez más un papel central a medida que el Imperio colapsaba bajo los bárbaros. En esas circunstancias, la tradición clásica se revelaba como la fuente más autoritativa, extendida y reconocida por todos, para tratar con aquellos problemas que aquejaban la Cristiandad. Por ello, en los textos analizados, la apelación constante a rechazar la jactancia, la soberbia y la violencia se hacen bajo el ropaje de términos que conservan la carga semántica con que los dotó la tradición clásica. De esta manera, los escritos del Pseudo Justino Mártir reactualizaron la noción clásica de la desmesura, asimilándola a la concepción cristiana de pecado y utilizándola como medio de censura de las expresiones desviadas o inconvenientes para la ortodoxia.

\section{Bibliografía}

\section{Fuentes primarias}

Allen, F. D. (1891). Prometheus Bound. Harvard University.

BiCKLEY Rogers, B. (1852). Aristophanous Nephelai $=\mathrm{T}$ he clouds of Aristophanes. The Greek Text with a Translation into Corresponding Metres and Original Notes. Francis Macpherson.

GodLEY, A. D. (1920). Herodotus (Vol. III). Cambridge.

JeBB, R. (1891). Sophocles: The Plays and Fragments, with critical notes, commentary, and translation in English prose. Part III: The Antigone. Cambridge University Press.

JEBB, R. (1892). Sophocles: The Plays and Fragments, with critical notes, commentary, and translation in English prose. Part V: The Trachiniae. Cambridge University Press. 
JeBB, R. (1894). Sophocles: The Plays and Fragments, with critical notes, commentary, and translation in English prose. Part VI: The Electra. Cambridge University Press.

KovACS, D. (1994). Euripides: Alcestis. Loeb Classical Library.

MAEHLER, H. (1971). Pindari carmina cum fragmentis: Nemeas (5th edn.). Teubner.

MAIR, A. W. E MAIR, G. R. (1927Callimachus: Hymns and Epigrams, Lycophron and Aratus. Loeb Classical Library.

Mazon, P. (1928). Hesiode: Théogonie. Collection des Universites de France.

MigneS, J. P. (1857). Patrologia Graeca (Tomus VI).

MonRo, D. B. E Allen, Th. W. (1920a). Homeri Opera in Five Volumes: Illiad. Oxford University Press.

Monro, D. B. E Allen, Th. W. (1920b). Homeri Opera in Five Volumes: Odyssey. Oxford University Press.

MurRAY, G. (1913). Euripidis Fabulae III: Orestes. Oxford Clarendon Press.

MuRAY, G. (1955). Aeschyli tragoediae: Agamemnon (2nd edn.) Oxford Clarendon Press.

SEATON, R.C. (1912). Apolonius Rhodius: Argonautica. Loeb Classical Library.

VERITY, A. (2003). Theocritus. Idylls. Oxford University Press.

VON WiLAmOWITZ-MOELLENDORFF, U. (1897). Hymns and Epigrams. Callimachus. Weidmann.

White, E. (1914). Works and Days, Hesiod, Homeric Hymns, Epic Cycle, Homerica. Loeb Classical Library.

\section{Bibliografía crítica y traducciones}

APARICIO, L. M. (2007). Aristófanes. Comedias II. Gredos.

BRIOSO SÁNCHEZ, M. (Ed.) (1986). Bucólicos griegos. Akal.

CAMpeggiani, P. (2012). Prepotencia y abuso en el derecho ático: a propósito del concepto de hybris. Habis, 43, 27-46. http://institucional.us.es/revistas/habis/43/art_2.pdf.

CAPOMACCHIA, A. M. (2004). L'eroe mangia: il pasto nella dimensione della hybris eroica. 'Illu. Revista de Ciencias de las Religiones, 12, 9-14.

CRESPO GÜEMES, E. (1996). Homero. Ilíada. Gredos.

de Cuenca y Prado, L. A. y Brioso Sánchez, M. (1980). Calímaco. Himnos, epigramas y fragmentos. Gredos. FERNÁNDEZ, Á. (2012). La soberbia de Creonte. http://www.academia.edu/5701415/La soberbia_de_Creonte.

García TeljeIRo, M. y Molinos TejadA, M. T. (1986). Bucólicos griegos. Teócrito, Mosco, Bión. Gredos.

LASSO DE LA VeGA, S. (1981). Sófocles. Tragedias. Gredos.

Montes DE OCA, I. (1883). Píndaro. Odas. Luis Navarro Editor. 
PABÓN, J. M. (1993). Homero. Odisea. Gredos.

PereA, B. (1982). Esquilo. Tragedias. Gredos.

PÉREZ JimÉnEZ, A. y Martínez Diez, A. (1978). Hesíodo. Obras y fragmentos. Gredos.

Redondo, J. (1999). Calímaco. Himnos y epigramas. Akal.

SCHRADER, C. (1985). Heródoto. Historia VII. Gredos.

VAlVerde SÁnchez, M. (1996). Apolonio Rodio. Argonáuticas. Gredos.

Verde Castro, C. V. (1996). "Nemea X" o el mito de los eternos valores. Synthesis, 3. http://www.fuentesmemoria.fahce.unlp.edu.ar/art revistas/pr.2461/pr.2461.pdf.

\section{Notas}

${ }^{1}$ Hom. Il. I, 1-2.

${ }^{2}$ La actitud excesiva de Agamenón también es remarcada por Esquilo en la obra que lleva por título el nombre de este soberano. Allí, el poeta censura la actitud impía y fuera de toda mesura de Agamenón al decidir sacrificar a su hija Ifigenia llamándolo $\tau \alpha \nu \tau o ́ \tau o \lambda \mu o v$, "que se atreve a todo" (A. Ag. 218-225).

${ }^{3}$ Hdt, VII, 103,2.

${ }^{4}$ Hdt, VII, 10.

${ }^{5}$ Call, $\mathrm{Fr}$, XCVI.

${ }^{6}$ S., Ant., 370-371.

${ }^{7}$ A., Pr., 235-238.

${ }^{8}$ Cf. S., El. 881.

${ }^{9}$ Cf. Hom., Od. XIV, 262; XVII, 431.

${ }^{10}$ Cf. E., Or. 1581; Hom., Il. 214.

${ }^{11}$ Cf. S., Tr. 887.

${ }^{12}$ Cf. 2 Co XII, 10.

${ }^{13}$ Cf. Hch XXVII, 10.

${ }^{14}$ Cf. Mt XXII, 6; Lc XI, 45.

${ }^{15}$ Cf. Ar, Nu., 1068-1069.

${ }^{16}$ Cf. CAPOMACCHIA (2004, pp. 9-14)

${ }^{17}$ Hom., Il., XVI, 52-55.

${ }^{18} \mathrm{Hes}, \mathrm{Op} ., 238-241$. 
${ }^{19}$ Cf. Hom., Od., XI, 593 y ss.

${ }^{20}$ CAmpeggiani (2012, p. 27)

${ }^{21}$ Hom., Il., XVI, 386-388.

${ }^{22}$ Hes., Op., 277-280.

${ }^{23}$ Hom., Il., XXIV, 602-609.

${ }^{24}$ Call., Fr. LXXV, 64-69.

${ }^{25}$ Cf. Call, Cer., VI, 24-115.

${ }^{26}$ Hes., Th., 514-516.

${ }^{27}$ A. R., A., 466-484.

${ }^{28}$ Hom., Il., IX, 558-564.

${ }^{29}$ Theoc, Buc. XXII, 207-211.

${ }^{30}$ Cf. Pi., N., X, 72.

${ }^{31}$ VERDE CASTRO (1996).

${ }^{32}$ MARTíN (2000, p. 115)

${ }^{33}$ Pseudo Justino, Epistula ad Diognetum, 496 B4-C2.

${ }^{34}$ Ídem, C4-C7.

35 Ídem, D3-D7.

${ }^{36}$ Pseudo Justino, Epistula ad Zenam et Serenum, 510 A5-A7.

${ }^{37}$ Pseudo Justino, Quaestiones Christianorum ad Gentiles, 195 B8-E1.

${ }^{38}$ Pseudo Justino, Epistula ad Diognetum, 495 B2-C3.

${ }^{39}$ Pseudo Justino, Expositio rectae fidei, 386 B9-C2.

${ }^{40}$ Pseudo Justino, Expositio rectae fidei, 386 D4-387 A3.

${ }^{41}$ Pseudo Justino, Expositio rectae fidei, 388 A7-B8.

${ }^{42}$ Pseudo Justino, Expositio rectae fidei, 379 D5-380 A6.

${ }^{43}$ Pseudo Justino, Quaestiones et responsiones ad orthodoxos, 440 A1-B3. 